\title{
Amylin inhibits ovariectomy-induced bone loss in rats
}

\author{
M-N Horcajada-Molteni ${ }^{1}$, M-J Davicco ${ }^{1}$, P Lebecque $^{1}$, V Coxam ${ }^{1}$, \\ A A Young ${ }^{2}$ and J-P Barlet ${ }^{1}$ \\ ${ }^{1}$ Métabolisme Minéral, U3 M, INRA Clermont-Theix, 63122 St-Genès Champanelle, France \\ ${ }^{2}$ Amylin Pharmaceuticals Inc., San Diego, California, USA \\ (Requests for offprints should be addressed to J-P Barlet; Email: horcajad@clermont.inra.fr)
}

\begin{abstract}
Amylin (AMY), a peptide co-secreted with insulin by pancreatic $\beta$-cells, inhibits bone resorption and stimulates osteoblastic activity. The ovariectomized (OVX) rat is an established animal model for human osteoporosis. Thus, the present experiment was performed to study the effects of AMY on estrogen deficiency-induced bone loss in rats. Thirty-one 6-month-old Wistar rats were randomized by body weight $(\mathrm{BW})$ into two groups. The first underwent surgical OVX $(n=21)$. The second was sham-operated $(\mathrm{SH} ; n=10)$. Sixty days after surgery, 11 OVX rats were s.c. injected with rat AMY $(3 \mu \mathrm{g} / 100 \mathrm{~g} \mathrm{BW} /$ day, for 30 days; OVX+AMY), and 10 with solvent alone in the same way $(0.15 \mathrm{ml} / 100 \mathrm{~g} \mathrm{BW}$; OVX). Each rat, housed in an individual cage, was fed daily the mean quantity of diet consumed the day before by $\mathrm{SH}$ rats. This diet contained $0 \cdot 24 \%$ calcium and $0 \cdot 16 \%$ phosphorus. The 31 animals
\end{abstract}

were killed on day 90. No difference in daily weight gain and BW was observed between groups. Neither AMY treatment nor OVX had any significant effect upon femoral morphology, femoral failure load, diaphyseal femoral density (representative of cortical bone) and total femoral calcium content. Nevertheless, both distal metaphyseal (representative of cancellous bone) and total femoral bone densities were higher in SH and OVX+AMY than in OVX rats. The highest plasma osteocalcin concentration was measured in OVX+AMY rats. Simultaneously, urinary deoxypyridinoline excretion was lower in OVX+AMY than in OVX rats. These results indicate that in OVX rats, AMY treatment inhibited trabecular bone loss both by inhibiting resorption and by stimulating osteoblastic activity.

Journal of Endocrinology (2000) 165, 663-668

\section{Introduction}

Amylin (AMY) is a 37 amino acid hormone structurally similar to calcitonin-gene-related peptide (CGRP) (Cooper et al. 1987) and to the calcitonins at the N- and C-termini (Young et al. 1995). AMY is mostly expressed in pancreatic $\beta$-cells, from which it is co-secreted with insulin in response to nutrient stimuli (Ogawa et al. 1990). AMY is absolutely or relatively deficient in conditions of $\beta$-cells loss, such as type 1 diabetes and late type 2 diabetes mellitus. AMY receptors of the type found in nucleus accumbens (Beaumont et al. 1993) and area postrema have been elusive. Their pharmacology has recently been shown to be produced by the co-expression of calcitonin C1a receptors and receptor activity modulating protein (RAMP1) (Muff et al. 1995, Christopoulos et al. 1999) in a manner similar to the formation of CGRP receptor from calcitonin receptor-related receptor and RAMP1 (MacLatchie et al. 1998).

Despite nearly 60 reported actions of AMY, its physiological role is poorly understood. Its most potent (physiological) metabolic actions, including inhibition of gastric emptying, inhibition of food intake, inhibition of pancre- atic enzyme secretion and inhibition of glucagon secretion, are consistent with a primary role in controlling the rate of glucose appearance in the plasma (Young 1997). In this way, AMY's function appears to complement that of insulin, which primarily controls glucose disposal.

In addition, AMY has potent effects to lower plasma calcium (Ca) concentration and inhibit osteoclast activity (Datta et al. 1989, MacIntyre 1989), and is reported to stimulate osteoblast growth (Cornish et al. 1995, 1998b, Romero et al. 1995). Although AMY is less potent than calcitonin at calcitonin receptors, it circulates at higher concentrations, and could represent a significant signal at such receptors (Zaïdi et al. 1993). Some of the AMY's skeletal actions appear to be mediated via mechanisms distinct from those of calcitonin (Alam et al. 1993). The lack of AMY in type 1 diabetes mellitus has been proposed as a mechanism explaining susceptibility to osteopenia in those patients (Zaidi et al. 1993) and treatment of type 1 diabetic subjects for 1 year with the AMY agonist pramlintide resulted in improvement of biochemical bone markers (Bone et al. 1999), particularly in postmenopausal female subjects. The reason that individuals with type 2 diabetes are not generally osteopenic is also 
probably substantially contributed to by the fact that their body weight $(\mathrm{BW})$ tends to be high, in contrast to patients with type 1 diabetes. Moreover, patients with type 2 diabetes typically display variable (but non-zero) fasting plasma AMY concentrations that are not modulated by meals (Van Daele et al. 1995).

The aim of the present study was to investigate the effects of AMY in a commonly used animal model of post-menopausal osteoporosis, the ovariectomized (OVX) rat (Kalu 1991, Wronski \& Yen 1991). Because OVX can increase food intake and body mass, and thereby affect bone density, while AMY can reduce food intake, the experiments were controlled by pair-feeding. They show effects of AMY on bone that indicate both inhibition of resorption and stimulation of osteoblasts.

\section{Materials and Methods}

\section{Animals and treatments}

These experiments were carried out in accordance with current legislation on animal experiments in France. The OVX rat develops osteopenia rapidly, within 3 months after surgery (Kalu 1991, Wronski \& Yen 1991). Thus, 31 virgin female Wistar rats weighing $324 \pm 4 \mathrm{~g}$ (mean \pm s.E.M.) were used at 6 months of age. On day 0 of the experiment, they were randomized by BW into two groups. Then, under chloral anesthesia, the first group underwent surgical OVX $(n=21)$. Other animals were sham-operated $(\mathrm{SH}, n=10)$. Sixty days after surgery, among the 21 OVX rats 11 were s.c. injected with synthetic rat AMY $(3 \mu \mathrm{g} / 100 \mathrm{~g} \mathrm{BW}$ per day, for 30 days; OVX+AMY) and 10 with solvent alone $(0.9 \%(\mathrm{w} / \mathrm{v})$ $\mathrm{NaCl}$ containing $0 \cdot 01 \% \mathrm{BSA}$; OVX). Each rat was housed individually in a plastic cage allowing separate collection of urine and feces, at $21{ }^{\circ} \mathrm{C}$, with a $12 \mathrm{~h}$ light: $12 \mathrm{~h}$ darkness cycle. Low-Ca feeding has been accepted as a method of increasing bone resorption and as one of the experimental models to reduce bone mass (Salomon 1971, Sissons et al. 1984). Thus, to stimulate bone resorption, the animals were fed a semi-purified $\mathrm{Ca}$-deficient diet containing corn starch (64\%), purified casein (18\%), alphacel non-nutritive bulk $(10 \%)$, ground nut oil $(2 \cdot 5 \%)$, rape oil $(2 \cdot 5 \%)$ and vitamins and mineral mixture $(3 \%)$ (Ca, $0 \cdot 24 \%$; phosphorus $(\mathrm{P}), 0 \cdot 16 \%)$. To prevent hyperphagia induced by OVX, the individual daily consumption was measured and each rat received the mean quantity of the chow consumed by SH rats during the previous day (about $20 \mathrm{~g} / \mathrm{rat}$ per day). Each animal was weighed weekly. Urine was collected during a $24 \mathrm{~h}$ period on day 89 of the experimental period to measure the excretion of $\mathrm{Ca}, \mathrm{P}$ and deoxypyridinoline (DPD), a marker for bone resorption (Robins 1994).

Rats were killed by cervical dislocation on day 90 . Blood was collected by cardiac puncture. After centrifugation, plasma was harvested and frozen until analysis.
The success of OVX was confirmed by a marked atrophy of uterine horns in both OVX and OVX+AMY rats. Femurs were cleaned from adjacent tissue and used for physical and chemical measurements.

\section{Physical measurements}

Femoral mechanical testing Immediately after collection, the length of the right femur and the mean diameter of the femoral diaphysis were measured using a caliper. Due to the irregular shape of the femoral diaphysis, the femoral diameter used in the calculation was the mean of the greatest and the smallest femoral diaphysis diameters. Then, each bone was placed in $0.9 \% \mathrm{NaCl}$ at $4{ }^{\circ} \mathrm{C}$. The mechanical resistance of the femoral bones was determined $24 \mathrm{~h}$ later, by using a three-point bending test. Each bone was secured on the two lower supports (diameter $4 \mathrm{~mm}$, length $20 \mathrm{~mm}$ ) of the anvil of a Universal Testing Machine (Instron 4501, Instron, Canton, MA, USA). The upper roller diameter was $6 \mathrm{~mm}$. The cross-head speed for all the tests was $0.5 \mathrm{~mm} / \mathrm{min}$. The load at rupture was automatically determined by the Instron 4501 software. To ensure comparable testing sites, the femur was always mounted so that the cross-head was applied just in the middle of the bone. Using female rats, the span of the specimen that was loaded was $20 \mathrm{~mm}$ to guarantee that $85-90 \%$ of the flexure of the bone was due to bending. This method of testing has been previously validated by using Plexiglas standard probes (Turner \& Burr 1993). Results are expressed in newtons.

Bone mineral density Dual energy X-ray absorptiometry measurements were made with a Hologic QDR4500A X-ray bone densitometer (Hologic France, Massy, France). Total femoral bone mineral density (T-BMD) was determined. Furthermore the BMDs of two subregions, one corresponding to the distal metaphyseal zone (M-BMD), which is rich in cancellous bone, and the other to the diaphyseal zone (D-BMD), which is rich in cortical bone, were measured (Pastoureau et al. 1995).

\section{Biochemical analysis}

Marker of osteoblastic activity Plasma osteocalcin (OC) concentrations were measured by homologous RIA using rat OC standard, goat anti-rat OC antibody, ${ }^{125} \mathrm{I}-$ labelled rat OC and donkey anti-goat second antibody (Biochemical Technologies kit, Stoughton, MA, USA). The lowest limit of detection was $60 \mathrm{pg} / \mathrm{ml}$, and the intraand inter-assay variations were 6.5 and $8.2 \%$ respectively.

Marker of bone resorption DPD in urine collected during the $24 \mathrm{~h}$ before killing was measured by an IRMA assay using a Pyrilinks-D kit (Metra Biosystems, Mountain View, CA, USA). The assay of DPD required the addition of $50 \mu \mathrm{l}$ of urine sample (or DPD standard or control) to 
Table 1 Femoral length and mean femoral diameter in $\mathrm{SH}, \mathrm{OVX}$ and $O V X+A M Y$ rats (means \pm S.E.M., no significant difference was observed between groups)

\begin{tabular}{|c|c|c|c|}
\hline & OVX+AMY & OVX & SH \\
\hline _ength (mm) & $37 \cdot 3 \pm 0 \cdot 4$ & $36 \cdot 9 \pm 0 \cdot 4$ & $36 \cdot 5 \pm 0 \cdot 6$ \\
\hline Diameter (mm) & $3 \cdot 80 \pm 0 \cdot 07$ & $3 \cdot 80 \pm 0 \cdot 05$ & $3 \cdot 87 \pm 0 \cdot 05$ \\
\hline
\end{tabular}

each well of a DPD-coated microplate. The monoclonal antibody against DPD was added to the plate, and the free DPD in urine competed with the DPD coated on the plate for the antibody. A second antibody conjugated to alkaline phosphatase (goat anti-rabbit immunoglobulin G alkaline phosphatase) was added to bind with antibody against DPD. A substrate, p-nitrophenylphosphate, was added to produce a yellow color. Optical density was measured at $405 \mathrm{~nm}$. In our experimental conditions, the lowest limit of detection for the assay was $3 \mathrm{nmol}$. The intra- and inter-assay variations were 6 and 8\% respectively. Results are expressed as nanomoles DPD per millimole creatinine (Robins 1994). The urinary creatinine assay was used to adjust DPD values for variation in urine volume. This assay was based on a modified Jaffé method in which picric acid forms a colored solution in the presence of creatinine (Cook 1975).

Ca Ca was determined by atomic absorption spectrophotometry (Perkin Elmer 401, Norwalk, CT, USA) in plasma, urine and ashed bone samples diluted with $0 \cdot 1 \%$ lanthanum chloride solution. $\mathrm{P}$ was measured by colorimetry.

\section{Statistics}

Results are presented as means \pm S.E.M. A parametric one-way ANOVA was used to test for any differences among the groups. If the result was found significant $(P<0 \cdot 05)$, the Student-Newman-Keuls multiple comparison test was then used to determine the specific differences between group means. If a parametric ANOVA was not feasible (when there were significant differences between the standard deviations of the groups, tested by Kolmogorov-Smirnov test), a Kruskall-Wallis test followed by the Mann-Whitney Wilcoxon U-test was used to compare differences between groups.

\section{Results}

During the 90 days of the experimental period the mean BW of the 31 rats increased from $323 \pm 10 \mathrm{~g}$ to $379 \pm 11 \mathrm{~g}(P<0 \cdot 05)$. No significant difference in daily weight gain or BW was observed between groups.
Table 2 Plasma Ca concentration, urinary Ca excretion and femoral Ca content in $\mathrm{SH}, \mathrm{OVX}$ and $\mathrm{OVX}+\mathrm{AMY}$ rats (means \pm S.E.M.)

\begin{tabular}{|c|c|c|c|}
\hline & $\mathrm{OVX}+\mathrm{AMY}$ & ovx & SH \\
\hline Plasma Ca $(\mathrm{mM})$ & $3 \cdot 85 \pm 0.04^{*}$ & $4.04 \pm 0.03$ & $3.94 \pm 0.05^{\star}$ \\
\hline Urinary Ca (mg/day) & $3 \cdot 3 \pm 0 \cdot 3$ & $3 \cdot 3 \pm 0 \cdot 5$ & $4 \cdot 2 \pm 0 \cdot 2$ \\
\hline Femoral Ca (mg) & $149 \cdot 4 \pm 4 \cdot 3$ & $150 \cdot 3 \pm 4 \cdot 3$ & $158 \cdot 4 \pm 7 \cdot 9$ \\
\hline
\end{tabular}

${ }^{*} P<0.05$ vs OVX.

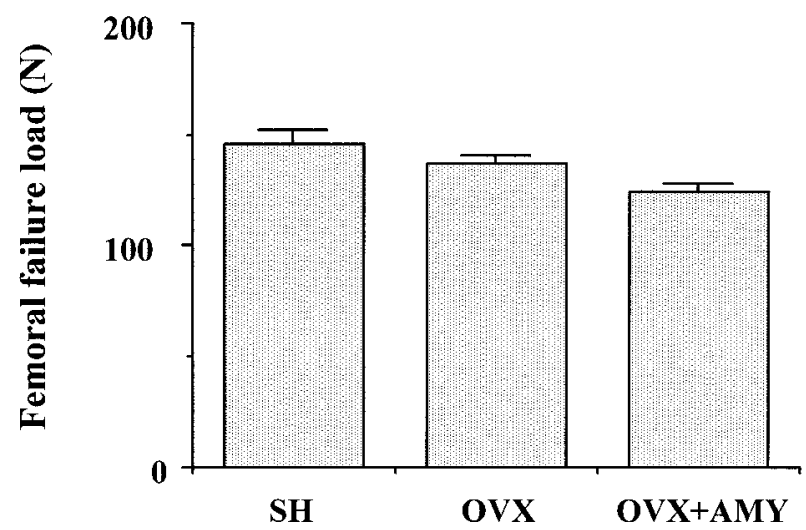

Figure 1 Femoral failure load measured in $\mathrm{SH}, \mathrm{OVX}$ and OVX+AMY rats. Means \pm S.E.M., no significant difference was observed between groups.

At necropsy, no significant difference in femoral length and mean femoral diameter was observed between groups (Table 1). In the same way, femoral failure load was not different in the three groups of rats (Fig. 1).

However, T-BMD was lower in OVX than in both $\mathrm{SH}$ and $\mathrm{OVX}+\mathrm{AMY}$ rats. No significant difference in D-BMD was observed between groups. M-BMD was lower in OVX than in SH or OVX+AMY rats. M-BMD was slightly but significantly lower in OVX+AMY than in $\mathrm{SH}$ rats (Fig. 2). No significant difference in femoral $\mathrm{Ca}$ content or urinary $\mathrm{Ca}$ excretion was observed between groups. Plasma Ca concentration was higher in OVX than in $\mathrm{SH}$ or $\mathrm{OVX}+\mathrm{AMY}$ rats, but it was not different in $\mathrm{SH}$ or OVX+AMY rats (Table 2).

The highest value for plasma OC concentration $(22.3 \pm 0.8 \mathrm{ng} / \mathrm{ml})$ was measured in OVX+AMY rats. It was not different from that simultaneously measured in OVX rats, but it was higher than in SH rats. Urinary DPD excretion measured in OVX $(166 \pm 12 \mathrm{nmol} \mathrm{DPD} / \mathrm{mmol}$ creatinine) was higher than that measured in OVX+AMY or SH rats. It was also slightly but significantly higher in OVX+AMY than in SH (Fig. 3).

\section{Discussion}

In the present study, treatment of OVX rats with $3 \mu \mathrm{g} /$ $100 \mathrm{~g} \mathrm{BW}$ per day of rat AMY for 30 days fully or partly 

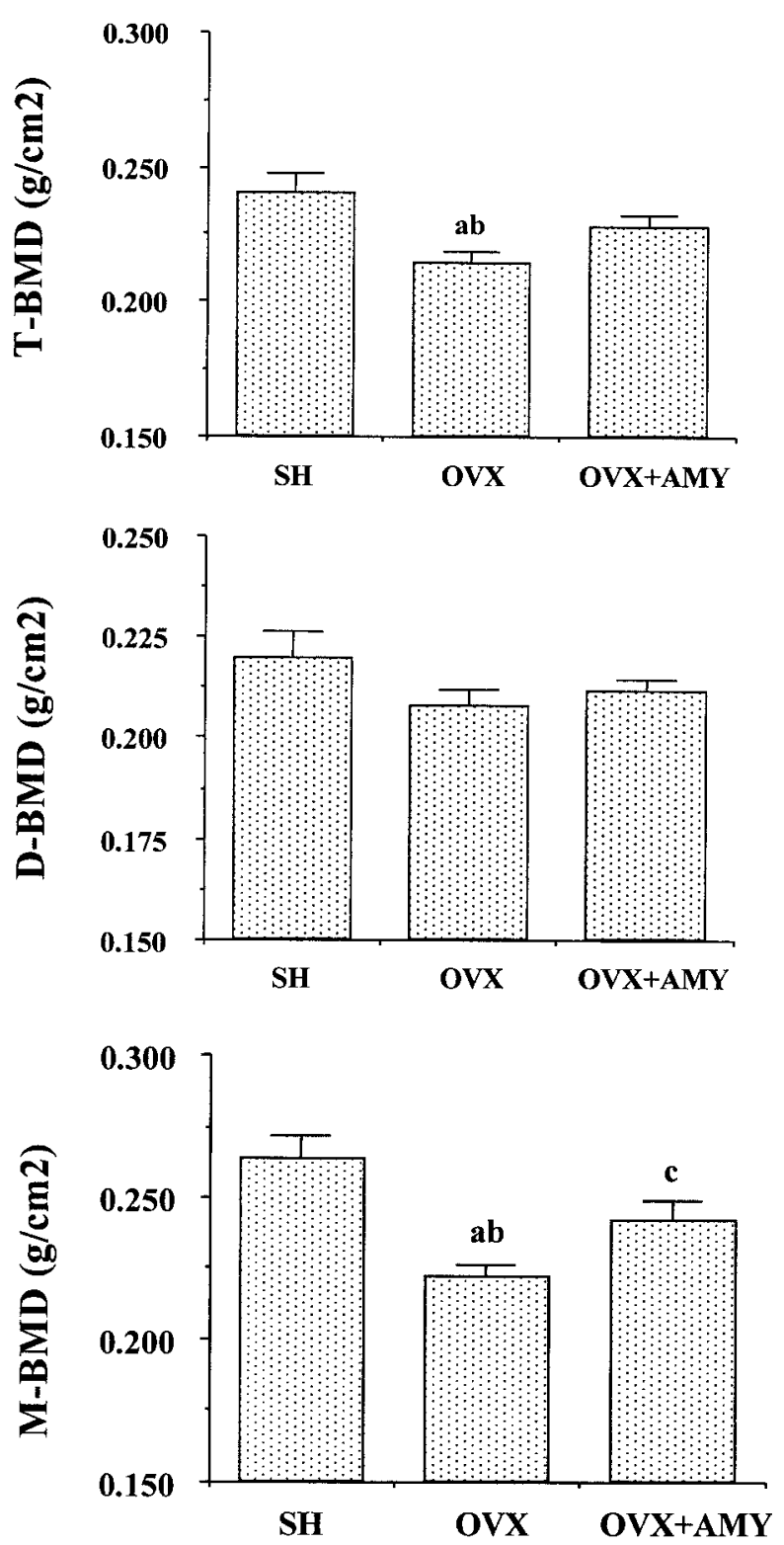

Figure 2 T-BMD, D-BMD and M-BMD femoral density measured in $\mathrm{SH}, \mathrm{OVX}$ and $\mathrm{OVX}+\mathrm{AMY}$ rats. Means \pm S.E.M., ${ }^{\mathrm{a}} \mathrm{P}<0 \cdot 01$ vs $\mathrm{SH}$; ${ }^{\mathrm{b}} P<0 \cdot 05$ vs OVX+AMY; ${ }^{\mathrm{C}} P<0 \cdot 05$ vs $\mathrm{SH}$.

restored towards normal (as exemplified in SH rats) several physical and biochemical marker abnormalities that had developed during the 90 days after OVX. Plasma Ca concentration, elevated in OVX rats, was restored to the levels in SH rats with AMY (Table 2). Total and metaphyseal femoral density, but not diaphyseal density, was partly restored with AMY treatment (Fig. 2). Urinary DPD excretion was partly normalized by AMY treatment, indicating a reduction in resorptive activity, and plasma OC was elevated in AMY-treated animals, consistent with
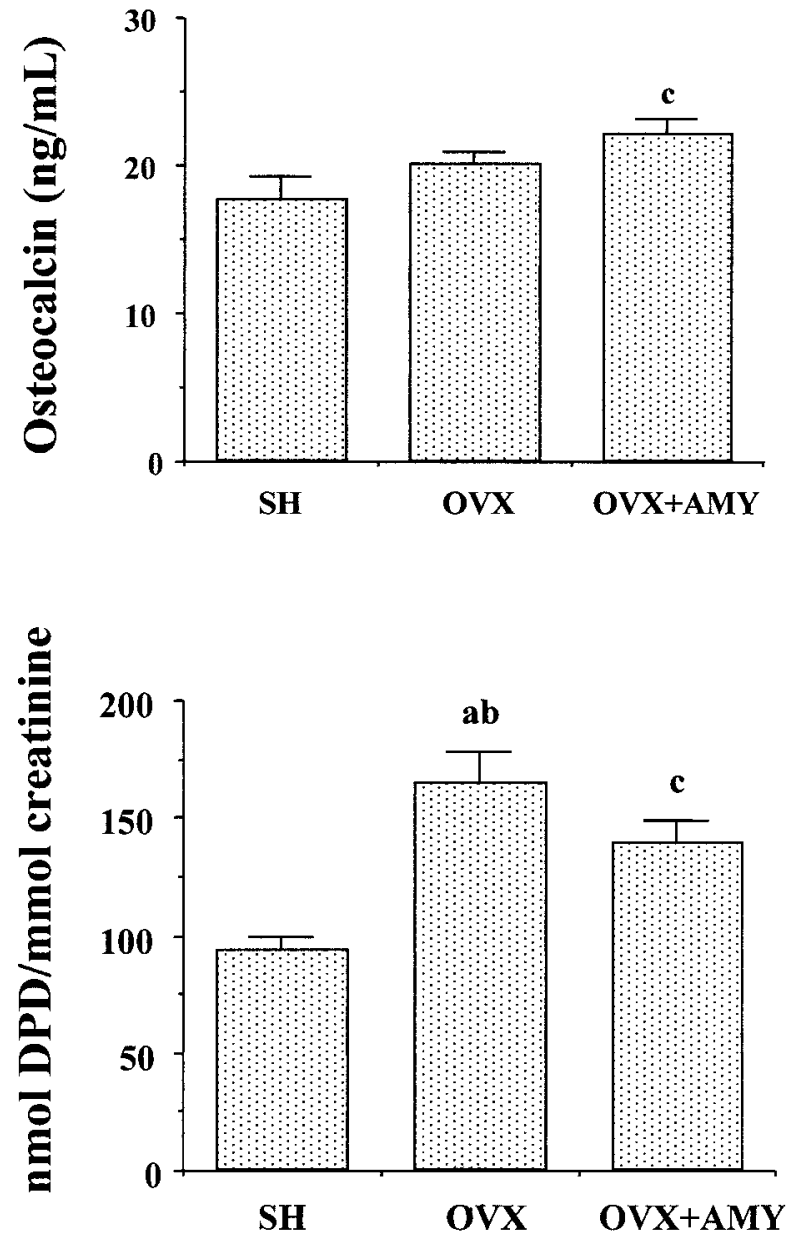

Figure 3 Plasma OC concentration and urinary DPD excretion measured in $\mathrm{SH}, \mathrm{OVX}$ and $\mathrm{OVX}+\mathrm{AMY}$ rats. Means \pm S.E.M., ${ }^{\mathrm{a}} P<0.01$ vs $\mathrm{SH} ;{ }^{\mathrm{b}} P<0.05$ vs OVX+AMY; ${ }^{\mathrm{C}} P<0.05$ vs $\mathrm{SH}$.

a stimulation of bone formation (Fig. 3). There were no significant differences between groups in femoral failure load, femoral Ca content and urinary Ca excretion (Fig. 1; Table 2).

While the $3 \mu \mathrm{g} / 100 \mathrm{~g}$ s.c. injection employed in the present experiment is predicted from kinetic studies (Young et al. 1996) to have raised plasma AMY concentrations to a supraphysiological $1 \mathrm{nM}$, the mean increment in $24 \mathrm{~h}$ exposure to circulating AMY can be calculated to be approximately $35 \mathrm{pM}$, a 2- to 3-fold increase over physiological concentrations. Thus, the present studies do not preclude a physiological, or near-physiological, effect of AMY on bone.

In vivo, AMY causes hypocalcemia in rats and rabbits and, in vitro, it inhibits bone-resorbing activity of rat osteoclasts (Datta et al. 1989). In the same way, in our experimental conditions, AMY treatment decreased plasma Ca concentration since the highest calcemia was 
measured in OVX rats, in which it was significantly higher than in $\mathrm{SH}$ or $\mathrm{OVX}+\mathrm{AMY}$ rats, while no difference was observed between these two groups (Table 2). An increase in plasma Ca concentration measured in OVX rats in the present study may have resulted from increased bone resorption since estrogen deficiency stimulates osteoclastic activity. Osteoclasts contain estrogen receptors and respond to estrogen in vitro by decreasing resorptive activity (Oursler et al. 1991, 1994) and blocking the production of proinflammatory cytokines by bone marrow and bone cells (Pacifici 1998). The loss of estrogen at menopause creates an imbalance of osteoblastic and osteoclastic activities such that bone resorption outpaces bone formation (Dempster \& Lindsay 1993, Horowitz 1993) leading to high turnover bone loss, post-menopausal osteoporosis and increased risk of fractures. Thus, in OVX rats, T-BMD and M-BMD (representative of trabecular bone) were lower than in SH or OVX+AMY rats, while no difference in D-BMD (representative of cortical bone) was observed between groups (Fig. 2). Such a lack of difference in D-BMD might partly explain while no difference in femoral $\mathrm{Ca}$ content was observed between groups (Table 2). Thus, AMY ameliorated bone loss more in trabecular than in cortical bone, perhaps explaining the absence of effect on femoral failure load in the present study (Fig. 1). The preventive effect of AMY treatment on OVX-stimulated trabecular bone resorption was reflected by urinary DPD excretion, lower in OVX+AMY than in OVX rats (Fig. 3).

AMY has been found to stimulate the proliferation of osteoblasts in a dose-dependent manner for concentrations as low as $10^{-11} \mathrm{M}$, and histomorphometric indices of bone formation are increased in vivo after the local injection of the peptide (Cornish et al. 1995, 1998b). In adult male mice given daily s.c. injections of AMY $(10 \cdot 5 \mu \mathrm{g}$, for 4 weeks) histomorphometric indices of bone formation increased 30-100\% in the AMY-treated group, whereas resorption indices were reduced by $70 \%$. Cortical width, tibial growth plate width, tibial length, body weight and fat mass were all increased in the AMY-treated group (Cornish et al. 1998a). Both an increase in osteoblastic activity and a decrease in bone resorption induced by AMY treatment is supported in the present study where plasma OC concentration was highest in the OVX+AMY group, in which urinary DPD excretion was simultaneously lower than in OVX rats (Fig. 3).

Romero et al. (1995) investigated the effects of AMY (100 pmol/100 g BW, s.c. for 19 days) on bone metabolism in normal and diabetic (streptozotocin-induced) rats. Analysis of the bone histomorphometry showed a low-turnover osteopenia in the diabetic animals. AMY administration resulted in a significant increase in bone volume in the normal rat, but was unable to significantly alter this parameter in diabetic rats. That study used a lower dose of AMY (about $0 \cdot 3 \mu \mathrm{g} / 100 \mathrm{~g} \mathrm{BW}$ vs $3 \mu \mathrm{g} /$ $100 \mathrm{~g} \mathrm{BW}$ ) during a shorter time (19 days vs 30 days), which might partly explain differences from the results reported here.

In conclusion, the present experiment indicates that, in OVX rats, AMY treatment partially inhibited estrogen deficiency-induced trabecular bone loss, by inhibiting resorption as well as by stimulating osteoblastic activity, as shown by decreased calcemia and urinary DPD excretion and increased plasma OC concentration measured in OVX rats treated with AMY. Thus, AMY appears as an attractive candidate as a therapeutic agent for osteoporosis.

\section{References}

Alam ASTM, Bax CMR, Shankar VS, Bax BE, Bevis PJR, Huang CLM, Moonga BS, Pazianas M \& Zaïdi M 1993 Further studies on the mode of action of calcitonin on isolated rat osteoclasts: pharmacological evidence for a 2nd site mediating intracellular $\mathrm{Ca}^{2+}$ mobilization and cell retraction. Journal of Endocrinology 136 7-15.

Beaumont K, Kenney MA, Young AA \& Rink TJ 1993 High affinity amylin binding sites in rat brain. Molecular Pharmacology 44 493-497.

Bone H, Hurley M, Goldstein H, Fineman M \& Kolterman O 1999 Effects of administration of pramlintide for 12 months on bone metabolism markers in people with type 1 diabetes. Endocrine Society 81st Annual Meeting: Programs and Abstracts, p. 447.

Christopoulos G, Perry KJ, Morfis M, Tilakartatne N, Gao Y, Fraser NJ, Main MJ, Foord SM \& Sexton P 1999 Multiple amylin receptors arise from receptor activity modifying protein interaction with the calcitonin receptor gene product. Molecular Pharmacology 56 235-242.

Cook JGH 1975 Factors influencing the assay of creatinine. Annals of Clinical Chemistry 12 219-232.

Cooper GJS, Willis AC, Clark A, Turner RC, Sim RB \& Reid KBM 1987 Purification and characterization of a peptide from amyloidrich pancreases of type 2 diabetic patients. PNAS 84 8628-8632.

Cornish J, Callon KE, Cooper GJ \& Reid IR 1995 Amylin stimulates osteoblast proliferation and increases mineralized bone volume in adult mice. Biochemical and Biophysical Research Communications 207 133-139.

Cornish J, Callon KE, King AR, Cooper GJS \& Reid IR 1998a Systemic administration of amylin increases bone mass, linear growth, and adiposity in adult male mice. American Journal of Physiology 275 E694-E699.

Cornish J, Callon KE, Lin CQX, Xiao CL, Mulvey TB, Coy DH, Cooper GJS \& Reid IR 19986 Dissociation of the effects of amylin on osteoblast proliferation and bone resorption. American Journal of Physiology 274 E827-E833.

Datta HK, Zaïdi M, Wimalawansa SKJ, Ghatei MA, Beacham JL, Bloom SR \& MacIntyre I 1989 In vivo and in vitro effects of amylin and amylin-amide on calcium metabolism in the rat and the rabbit. Biochemical and Biophysical Research Communications 162 876-881.

Dempster DW \& Lindsay R 1993 Pathogenesis of osteoporosis. Lancet i $797-801$.

Horowitz MC 1993 Cytokines and estrogen in bone: anti-osteoporotic effects. Science $260626-627$.

Kalu DN 1991 The ovariectomized rat model of postmenopausal osteoporosis. Bone and Mineral 15 175-191.

MacIntyre I 1989 Amylinamide, bone conservation, and pancreatic $\beta$ cells. Lancet ii 1026-1027.

MacLatchie LM, Fraser NJ, Main MJ, Wise A, Brown J, Solari R, Lee MG \& Foord SM 1998 RAMPs regulate the transport and ligand specificity of the calcitonin-like receptor. Nature 393 333-336. 
Muff R, Born W \& Fischer JA 1995 Calcitonin, calcitonin generelated peptide, adrenomedullin and amylin: homologous peptides, separate receptors and overlapping biological actions. European Journal of Endocrinology 133 17-20.

Ogawa A, Harris V, McCorkle SK, Unger RH \& Luskey KL 1990 Amylin secretion from the rat pancreas and its selective loss after streptozotocin treatment. Journal of Clinical Investigation 85 973-976.

Oursler MJ, Osdoby P, Pifferven J, Riggs BL \& Spelsberg TC 1991 Avian osteoclasts as estrogen target cells. PNAS 88 6613-6617.

Oursler MJ, Pederson L, Fitzpatrick L, Riggs BL \& Spelsberg TC 1994 Human giant cell tumors of the bone (osteoclastomas) are estrogen target cells. PNAS 91 5227-5231.

Pacifici R 1998 Editorial: cytokines, estrogen and postmenopausal osteoporosis - the second decade. Endocrinology 139 2659-2661.

Pastoureau P, Chomel A \& Bonnet J 1995 Specific evaluation of localized bone mass and bone loss in the rat using dual energy $\mathrm{X}$-ray absorptiometry subregional analysis. Osteoporosis International $\mathbf{5}$ 143-149.

Robins SP 1994 Biochemical markers for assessing skeletal growth. European Journal of Clinical Nutrition 48 S199-S209.

Romero DF, Bryer HP, Rucinski B, Isserow JA, Buchinsky FJ, Cvetovic M, Liu CC \& Epstein S 1995 Amylin increases bone volume but cannot ameliorate diabetic osteopenia. Calcified Tissue International 56 54-61.

Salomon CD 1971 Osteoporosis following calcium deficiency in rats. Calcified Tissue International 8 320-333.
Sissons HA, Kelman GI \& Marotti G 1984 Mechanisms of bone resorption in calcium-deficient rats. Calcified Tissue International $\mathbf{3 6}$ 711-721.

Turner CH \& Burr CB 1993 Basic mechanical measurements of bone: a tutorial. Bone 14 595-608.

Van Daele PLA, Stolk RP, Burger H, Algra D, Grobbee DE, Hofman A, Birkenhäger JC \& Pols HAP 1995 Bone density in non-insulindependent diabetes mellitus. The Rotterdam study. Annals of Internal Medicine 122 409-414.

Wronski TJ \& Yen CF 1991 The ovariectomized rat as a model for postmenopausal bone loss. Cells and Materials (Suppl 1) 69-74.

Young AA 1997 Amylin's physiology and its role in diabetes. Current Opinions in Endocrinology and Diabetes 4 282-290.

Young AA, Pittner R, Gedulin B, Vine W \& Rink T 1995 Amylin regulation of carbohydrate metabolism. Biochemical Society Transactions 23 325-331.

Young AA, Vine W, Gedulin BR, Pittner R, Janes S, Gaeta LSL, Percy A, Moore CX, Koda JE \& Rink TJ 1996 Preclinical pharmacology of pramlintide in the rat: comparisons with human and rat amylin. Drug Development Research 37 231-248.

Zaïdi M, Shankar VS, Huang CLH, Pazianas M \& Bloom SR 1993 Amylin in bone conservation: current evidence and hypothetical considerations. Trends in Endocrinology and Metabolism 4 255-259.

Received 10 September 1999

Accepted 20 January 2000 